\title{
MUJER Y PODER: REINAS, CONDESAS, ARISTÓCRATAS E INDÓMITAS GUERRERAS
}

\author{
WOMAN AND POWER: QUEENS, COUNTESSES, ARISTOCRATS AND \\ INDOMITABLE FEMALE WARRIORS
}

María Reyes Ferrer

Universidad de Murcia

\section{Resumen:}

Son muchas las mujeres que a lo largo de la historia han tenido una participación muy activa en la vida pública, bien sea por ejercer un cierto poder, bien por llevar a cabo acciones heroicas con destacable destreza e inteligencia. Mujeres que desempeñaron papeles importantes y ejercieron su influencia en varios ámbitos sociales e incluso en asuntos nacionales, desde la política y desde el campo de batalla, donde muestran su capacidad de acción y organización. Sin embargo, muchas de ellas pagaron un alto precio por su determinación en la vida pública, pues se consideraba que poseían una serie de atributos impropios de su sexo -pero aceptados en hombres- $y$, por consiguiente, sentenciados en ellas: mujeres guerreras, justicieras, estrategas, hábiles políticas y mediadoras, inteligentes, sabias y poderosas, sin una figura masculina que sustentara su poder. Mujeres que, de ser protagonistas indiscutibles de su tiempo, han pasado a vivir en los márgenes de la historia, debatiéndose entre el olvido y la leyenda por el hecho de haber abandonado los confines del silencio, desestabilizando de esta forma la barrera que divide el mundo doméstico y el mundo exterior.

\section{Palabras claves:}

Personajes históricos femeninos, mitos, Adriana Assini.
Abstract:

Many women throughout history have had a very active participation in public life, either by exercising a certain power, either by performing heroic actions with remarkable skill and intelligence. These women played important roles and were influential in various social areas and even on national issues, from politics to the battlefield, where they show their capacity for action and organization. However, many of them paid a high price for their determination in public life: it was considered that they had a series of improper attributes for women -but accepted in men- and therefore criticized: warriors women, avengers, strategists, clever political and mediators, wise and powerful women, without a male figure to substantiate their power. Women that were protagonists of their time, but after left on the margins of history, struggling in order not to be forgotten or become a legend just because they had left the confines of silence, thus destabilizing the barrier that divides the private world and the outside world.

\section{KEY WORD:}

Female historical figures, myths, Adriana Assini. 


\section{InTRODUCCIón}

Son muchas las mujeres que a lo largo de la historia han tenido una participación muy activa en la vida pública, bien sea por ejercer un cierto poder, bien por llevar a cabo acciones heroicas con destacable destreza e inteligencia. Mujeres que desempeñaron papeles importantes y ejercieron su influencia en varios ámbitos sociales e incluso en relevantes asuntos nacionales, desde la política y desde el campo de batalla, donde muestran su capacidad de acción y organización. Sin embargo, muchas de ellas pagaron un alto precio por exhibir su pensamiento y determinación en la vida pública, pues se consideraba que poseían una serie de atributos impropios de su sexo -pero aceptados en hombres- $y$, por consiguiente, sentenciados en mujeres. Nos referimos a guerreras, justicieras, estrategas, hábiles políticas y mediadoras, inteligentes, sabias y poderosas, cuyo principal problema fue la carencia de una figura masculina que sustentara su poder. Mujeres que, de ser protagonistas indiscutibles de su tiempo, han pasado a vivir en los márgenes de la historia, debatiéndose entre el olvido y la leyenda por el hecho de haber abandonado los confines del silencio, desestabilizando de esta forma la barrera que divide el mundo doméstico y el mundo exterior.

El presente trabajo tiene como objetivo el estudio de los personajes históricos femeninos que aparecen en la obra de Adriana Assini y cómo la escritora rompe con los estereotipos y los mitos a los que han estado expuestas, tanto en la historia como en la literatura, las mujeres que gozaron de un cierto poder.

\section{Desmitificando mitos, (re)construyendo historias: la obra de Adriana Assini}

La figura de Adriana Assini, escritora y pintora romana, supone una gran revelación dentro del panorama cultural e intelectual de nuestros días, contribuyendo de manera muy intensa al debate de la imagen de la mujer en la historia y aportando una nueva mirada al pasado y al presente a través de su pintura y la escritura. Se podría decir que es una de las herederas que continúa con la labor que las escritoras del primer y segundo Novecento comenzaron: la revisión de la historia desde lo privado y a través de la subjetividad. Dada su contemporaneidad, sería difícil enmarcar su obra dentro de un particular movimiento literario o cultural de Italia. No obstante, es posible afirmar que sus obras están en la línea de la novela histórica femenina post-moderna debido al interés por el pasado y la reescritura de éste, el análisis de la historia desde una posición crítica con las fuentes oficiales ${ }^{1} \mathrm{y}$, de manera especial, la recuperación del interés por

1 Estas novelas logran el cuestionamiento del texto por medio de la incorporación de ciertas técnicas narrativas. Los rasgos principales son la mezcla de historicidad e imaginación; la recreación del pasado que puede generar críticas del presente; la incorporación del género policíaco o la novela detectivesca; la distorsión consciente de la historia; la ficcionalización de personajes históricos; la metaficción; la intertextualidad; el dialogismo; el carnaval; la parodia; la heteroglosia; y la polifonía (Menton, 1993: 42-45). la pequeña historia, cotidiana e íntima, que permite la penetración psicológica en el personaje, generalmente femenino.

Para ello Assini se sirve de su pincel y su pluma y hace un uso propio de cada una de ellas con un objetivo común: valorar y dignificar el universo femenino, especialmente en el ámbito de la historia. Este es el centro de su arte, una necesidad, una forma de hacer justicia, un placer: “La donna è presente sempre nella mia produzione artistica. Mi piace raccontarne le vicissitudini storiche e le molteplici dimensioni metastoriche e simboliche" (Assini en Matrone, 2013). Sus obras rompen con esa supuesta fidelidad al texto histórico evidenciando las carencias que presenta la historiografía y, a su vez, incorporando una perspectiva descentralizada de los hechos.

Su producción literaria es abundante y, a día de hoy, mantiene dicha actividad en continuo movimiento. Ha publicado doce novelas históricas, cuatro relatos cortos y ha participado en diversos eventos poéticos, obteniendo varios premios y reconocimientos a su obra². En lo que concierne a sus novelas, Assini comenzó a publicar en los años noventa y ya en sus primeras novelas es posible distinguir ciertos aspectos característicos de su obra que se repetirán en la gran mayoría de sus novelas y marcaran un estilo muy personal.

Un elemento constante en su obra es la insistencia y reivindicación de un lugar en la historia y en el mundo para las mujeres. La palabra y la imagen aparecen como elementos inseparables con un objetivo común: contar historias enmarcadas dentro de un preciso contexto histórico minuciosamente documentado. Su interés por la historia está ligado no sólo al conocimiento del pasado sino también al entendimiento y el fuerte compromiso que mantiene con el presente: "Ho fatto presto mio il concetto per capire il presente bisogna conoscere il passato e per questo scrivo i miei romanzi con lo sguardo rivolto all'indietro, scegliendo di raccontare storie di donne e di uomini di un tempo lontano dal nostro" (Assini, 2013)

Califica la historia como un "serbatoio della nostra memoria remota, il pilastro della nostra identità culturale" (Assini, 2008) y, aun así, mantiene que esta es una disciplina que todavía está por reescribir, pues no es ni definitiva ni objetiva. Es por ello que sus novelas no se limitan a reproducir la historia, sino que trabaja en la (re)interpretación de las fuentes y el ingenio, tratando de rellenar los espacios vacíos -es decir, aquellos lugares que no están en las bibliotecas ni en los libros- con su imaginación, dándoles voz a sus personajes e imaginando a su vez tantos otros que podrían haber vivido allí, recreando vivencias a través de un viaje en el tiempo: "Ma viaggiare non è soltanto

2 Respecto a los premios obtenidos por su poesía, destacar: $2^{\underline{0}}$ premio en el "Concorso Nazionale d Poesia Marguerite Yourcenar", 2001; Medalla de oro en el "Concorso Nazionale di Poesia Città di Pompei", 2002; Medalla de oro en el "Concorso Spazio Donna" en Striano, 2005; Mención especial en el "Premio Paestum", 2005; 1ํpremio en el "Concorso Centro Polivalente di Sant'Agata dei Goti", 2006.

Revista Internacional de Culturas y Literaturas, abril 2014 ISSN: $1885-3625$ 
mettersi in macchina o prendere un aéreo. La mente è forse il maggiore mezzo di trasporto a nostra disposizione e ci conduce dove vogliamo, nel tempo e nello spazio". (Assini en González de Sande, 2011: 10).

Para revivir la historia, que nunca va más allá del siglo XVIII ${ }^{3}$, Assini cuenta con un gran número de personajes emblemáticos y a su vez polémicos $\mathrm{y}$, mediante una minuciosa indagación psicológica, la autora desnuda a los personajes e intenta restablecer una dignidad que la historia les arrebató. Son pocos los escritores que hasta ahora se han cuestionado la legitimidad de los datos oficiales y el porqué muchos personajes históricos son y serán siempre recordados como figuras problemáticas, muy probablemente sin merecerlo. Se podría decir que la escritora, en la línea de la historiografía feminista y la tradición post-moderna, busca una verdad distinta a la oficial, reinterpreta el discurso oficial de la historia y lo cuestiona contribuyendo, de esta forma, a dar una oportunidad para justificarse a todas aquellas mujeres de la historia que han sido marginadas y/o malinterpretadas por quienes las conocieron. Como se ha comentado, la escritora siente una especial debilidad por las figuras femeninas quienes son a su vez víctimas y heroínas de su propio tiempo, que en un determinado momento de la historia fueron silenciadas y/o separadas de su verdadera identidad femenina.

La Historia está llena de falsedades, prejuicios y mentiras, pero cuando se habla de mujeres todo se multiplica. Son muy pocas las mujeres que tienen un espa en las páginas de las antologías escó́sticas y, a menudo, de estas pocas mucio en las páginas de tan hechos y comportamientos que no corresponden a la realidad (Assini, 2011)

De una forma u otra, la figura femenina adopta una posición de inferioridad en la historia, tanto por su evidente ausencia como por los estereotipos, mitos y prejuicios que han acompañado a las mujeres a lo largo de los años. En consecuencia, el vínculo de esta escritora con la historia va más allá de la propia opción personal dado que considera que el hecho de conocer el pasado es una obligación, al igual que lo es desmentir y corregir las falsedades que inundan la literatura y los libros de historia. A través de la minuciosa indagación del pasado, Assini rehabilita, especialmente, a mujeres del pasado gracias a su perspicaz mirada crítica hacia la historia, desafiando ciertos presupuestos históricos anclados en el tiempo y proponiendo otra lectura de la historia:

Il alcuni casi, una rilettura critica rigorosa di taluni eventi, una inesperata scoperta archeologica o qualche fortunato ritrovamento di importanti documenti negli

3 "Mi interessa il periodo che va dal Medioevo al Settecento, ed è lì che vado a cercare le mie storie, tutte basate su eventi e personaggi realmente accaduti ma pieni di vuoti storiografici" (Assini en Guarnieri, 2001: 64) archivi e nelle biblioteche, sono sufficienti per rimettere in discussione conoscenze consolidate da secoli. (Assini, 2008)

Como la misma escritora afirma, su trabajo consiste tanto en investigar los sucesos históricos como indagar en la psicología de los personajes, "dialogar" con ellos, para poder así reconstruir sus personalidades mediante los datos oficiales y un tanto de fantasía. Esa historia oficial es en parte (de)construida por la autora, mezclando hechos y ficciones, lo verdadero con lo verosímil, mostrando su parte de escritora y su parte de historiadora. Y todo ello es posible siempre y cuando la historia se interprete como una disciplina susceptible de ser modificada, un campo de estudio que no es ni definitivo ni objetivo, por lo que siempre estará expuesta a un constante cambio. Por ello, con una gran habilidad, conjuga perfectamente la fuerza poética con la sensibilidad pictórica: los ambientes, el lenguaje, los movimientos.

Adriana Assini, Arianna contemporanea, sa come condurci in un labirinto di passioni personali, storiche, sociali; [...]riconstruisce fatti e personaggi con date e nomi presenti su tutti i libri di storia, aggiungendo sapientemente molto piu di quanto si riferisce in essi. Voglio dire che mette in pratica, in tempi decisamente non sospetti di 'manzonismo', la teoria manzoniana ${ }^{4}$-espressa nella fondamentale "Lettera a Monsieur Chauvet"- sullo strettissimo, vitale, rapporto tra "storia e poesia" (Aversa, 2009)

En las novelas de Assini se aprecia el esfuerzo por construir un puente entre la disciplina histórica y la literatura, la realidad y la fantasía, siempre con unas sólidas bases en la historia y centrada en la exploración de los personajes de
pasado y en su cotidianidad.

L'Autrice ha una particolare abilità nel convogliare eventi storici e quotidianità dei personaggi in un racconto sempre fluido. Inoltre opera un raro miracolo d'equilibrio nell'elaborazione di un linguaggio che mescola insieme ritmi moderni e toni dal sapore antico (Repetto, 2011).

\section{Mujer y poder: personajes históricos en las obras de Assini}

Assini delinea con gran pericia los personajes que viven en sus novelas, haciendo de éstos el aspecto más logrado, sin duda, de su obra. La escritora siente la necesidad de dar voz a las mujeres cuyas vidas han sido tradicionalmente interpretadas por el juicio masculino, con un resultado nefasto para ellas.

4 Aprovechando la mención a "la teoría manzoniana" a la que se refiere Aversa, considero de importancia hacer una breve precisión que Paola Carù hizo a propósito de la relación de Anna Banti y Manzoni, y que se puede aplicar al trabajo de Adriana Assini. Banti, en su artículo "Romanzo e Romanzo storico" (1951) critica el hecho de que Manzoni diferenciara entre el "fatto avvenuto" y el "fatto inventato", sin dejar un espacio al "fatto supposto". La escritora se atribuye una ventaja al tener en consideración el "fatto supposto", es decir, recrear una compleja historia del pasado a través de hechos "oficiales" con hipótesis probables (Carù: 1999: 88). Esta es la ventaja de Assini, quien construye hechos probables y deja margen para la reinterpretación de la historia, sin necesidad de considerar lo "no oficial" como algo "no posible" y únicamente ficticio. 
La diversa visione del mondo, la diversa scala di valori femminile, avrebbe reso giustizia a quel popolo di donne -siano esse regine, letterate o scienziate- che ci sono state raccontate dalla penna degli uomini, secondo il loro metro di giudizio e -non ultime- secondo le loro ossessioni sessuali? (Assini, 2009)

La autora hace un recorrido por las vidas de Juana I de Castilla, Erzsébet Báthory Shammuramat o Semiramide, Giulia Tofana, Girolama Spinola ${ }^{5}$ y Juana de Arco. Todas estas mujeres tuvieron cierto poder e influencia en su época, ya sea por su abolengo o por sus heroicas acciones que lograron desarrollar con pericia e inteligencia. Es por ello que Assini elige a estas heroínas, anónimas e históricas pero, al fin y al cabo, mujeres valientes y rebeldes:

Mi piacciono le donne forti, disposte a pagare anche prezzi altissimi pur di non piegare la testa, donne che combattono malgrado le sconfitte, che ci insegnano prima di tutto il valore dell'autostima, cioe a credere in se stesse anche quando si hanno tutti contro (Assini en Guarnieri, 2011: 65)

La implicación social y política de estas mujeres les ofreció la posibilidad de formar parte de las nuevas circunstancias de sus países, de decidir e influir con su opinión y sabiduría en la vida pública teniendo así la oportunidad de experimentar otras realidades, algo que terminarán pagando con su propia vida ${ }^{6}$. Llama la atención que figuras tan influyentes en su tiempo, mujeres tan poderosas, finalizaran sus vidas de manera insignificante, cruel e indigna: tal y como recoge la historia, Juana I de Castilla y la condesa Báthory terminaron sus días encerradas en castillos, Semiramide fue destronada por su hijo, Giulia y Girolama, tras ser torturadas, fueron ejecutadas y Juana de Arco fue otra víctima más de la hoguera. Las dos reinas, la condesa y la guerrera se convirtieron así en cuerpos biopolíticos, todas ellas fueron utilizadas como instrumento del poder para diversos fines y más tarde todas fueron sacrificadas. E caso de las fattucchiere es diverso, pues ellas mismas fabricaron el instrumento de poder, siendo precisamente ejecutadas por tener el poder sobre la vida y la muerte, tomándose la justicia por su cuenta.

La desaparición de estas mujeres es el precio que tuvieron que pagar para que se reestableciera un orden previo. A todas se les puede quitar la vida impunemente ya

5 La gran parte de escritores e historiadores que han recogido la historia de Giulia Tofana se refieren a su compañera Girolama como Spera o Spana de apellido y no como Spinola. Según Marcello Benfante (2008), Spinola corresponde al apellido de una cierta Maria, conocida como la Grifola, y que señala su implicacion en la difusion del veneno pues conocía el arte debido a sus conocimientos de brujería. Además, en varias fuentes la relación que se establece entre Giulia y Girolama es de madre e hija en lugar de hermanas.

6 Mariella Pandolfi (1991) mantiene que el mundo de la acción y del deseo femenino puede unicamente hacer recorridos internos, domésticos, pero fuera de estas lineas y una vez que éstos son descubiertos, se trasladan a la dimensión de culpa, enfermedad y soledad. Es el caso de las mujeres que se presentan, cuyas acciones y deseos sobrepasan lo privado, y por ello son penalizadas con sus vidas. que todas están sujetas a la voluntad política del momento, una fuerza que decide si su vida es digna de continuar o no. De la relectura crítica de las fuentes históricas se puede extraer que la vida de Juana I de Castilla fue manipulada por su padre y su marido por miedo a que ella reuniera el poder que ambos deseaban; Erzsébeth Báthory dependió de las decisiones de György Thruzó, su familiar y a su vez conde, quien no perdió la oportunidad de arrebatarle su poder cuando la condesa enviudó Semiramide fue desterrada por su hijo, quien ambicionaba la corona de su madre, Juana de Arco fue juzgada por un tribunal eclesiástico, cuyos miembros temían que la religiosidad de la mujer se impusiera sobre la iglesia haciendo de ésta una institución prescindible para llegar a dios y, por último, Giulia y Girolama fueron víctimas de una justicia que poco favorecía a las mujeres ${ }^{\underline{Z}}$. Se podría decir que todas ellas comparten el estigma de ser doblemente marginadas, por ser mujeres y por ser extraordinarias, algo que no será bien recibido por sus contemporáneos quienes las condenarán a una vida de represión y castigo.

Aún así, estas mujeres y sus trágicos destinos no encontrarán su eco en la historia sino más bien en la literatura, en un espacio tradicionalmente más subjetivo e irracional. María Zambrano ${ }^{8}$ elaboró la teoría sobre el espacio ocupado por los sexos, donde el masculino encontraba su lugar en la razón y la historia -lo objetivo-, mientras que el espacio femenino estaba relegado a un lugar oculto y cuya existencia es subjetiva, más propia de la poesía. Respecto a la escasa presencia en la historia, como Assini comenta, el número que ocupan las mujeres en las antologías históricas, literarias o de cualquier disciplina es dramáticamente inferior al de los hombres. Raramente son las mujeres las protagonistas que llenan las páginas de la historia a pesar de los grandes actos que pudieran perpetrar en vida, algo que llama la atención, sobre todo si se observa el protagonismo que se les cede a sus homólogos masculinos. Si a las mujeres se les ha negado un espacio racional, esto quiere decir que viven en un lugar irracional que las

7 Respecto a los finales de Semiramide y de Giulia y Girolama, es díficil determinar si verdaderemente fueron estos u otros. De Semiramide se dice que fue asesianada por su hijo, como muchas fuentes aluden, entre otras, Moormann, E., Uitterhoeve, W., De Adriano a Zenobia, Madrid, Akal, 1998, Cantú, C., Compendio de la historia universal, Madrid, Gaspar \& Roig, 1867; Castellanos de Zubiría, S., Las mujeres más perversas de la historia, Bogotá, Editorial Norma, 2008. De Giulia y Girolama tampoco se sabe con certeza su final, pues se cree que Giulia pudo ser encerrada en un convento y Girolama ejecutada, tal y como Stefania Bonura (2011) apunta, o ambas ajusticiadas, como Adela Muñoz Páez (2012) afirma. Assini, en sus novelas, escribe un desenlace diverso para Semiramide y Giulia, quienes no perderán su vida, aunque si lo hará Girolama, pero por otras causas.

8 "La mujer, sumergida en la vida, no ha alcanzado más que la perdurabilidad subterránea; su acción es imperceptible por confundirse con la vida misma, con cuyas fuentes ha mantenido siempre una secreta alianza. La Historia es una forma de objetividad, y por tanto de desprendimiento de la vida; es ya una cierta muerte, como lo es toda forma de objetividad" (Zambrano, 1987: 80). Según la estudiosa, a la mujer no le ha sido posible alcanzar la objetividad, bien porque la ha rechazado al comprender que vive en otro tipo de realidad y, por lo tanto, nada es objetivo, o bien porque los hombres son quienes hacen la historia y no han llegado a aprehender su existencia. 
ha alejado del concepto humano, dando lugar a una representación femenina "bajo distintas figuras terribles de los mitos y de la historia" (Balza, 2009: 59).

"Lo humano" es el contenido de la definición del hombre, y la mujer quedaba siempre en los límites, desterrada y, como toda realidad, rechazada, infinitamente temible. Solo en su dependencia al varón, su vida cobraba ser y sentido; más en cuanto asomaba en ella el conato del propio destino, quedaba convertida un extrano ser sin sede posible. transformaba en hechicera. (Zambrano 1987: 80)

Efectivamente, estas mujeres han trascendido el ámbito de la historia y se les ha dado una existencia poética, apartándolas a un lugar donde aparecen como figuras erráticas, mitos y mujeres malditas que nunca tuvieron una existencia propia, ni un espacio en la historia, principalmente porque ésta está escrita por hombres que no se interesaron por su presencia. Todos estos mitos y leyendas que se han construido alrededor de las figuras femeninas, en general, han contribuido a alimentar el imaginario occidental de la mujer, propiciando la aparición de arquetipos femeninos que no favorecen para nada a las mujeres. Cierto es que la historia ha dado lugar a tales interpretaciones y la literatura ha contribuido a especular y fantasear con estas mujeres, hasta llegar al punto de contaminarse mutuamente y hacer de la mujer un ser que roza lo mitológico. En consecuencia, las pocas mujeres que logran escapar al olvido, en muchas ocasiones, se representan con hechos y comportamientos que no corresponden a la realidad, entrando más bien en el territorio de la leyenda, de la literatura, del monstruo.

\section{Me gusta pensar que si quienes trasmitieron las historias de las heroínas que he elegido como protagonistas de mis novelas hubieran sido mujeres, hoy día no hablaríamos de Semiramide como la soberana lujuriosa y cruel, no llamaríamos "loca" a la reina Juana I ni tampoco pensaríamos en Erzsébet Báthory como la} "hiena de los Cárpatos" (Assini, 2011)

Toril Moi define con gran exactitud quién es realmente esa mujer a la que la literatura ha convertido en un personaje casi de ficción, en un monstruo: “El monstruo mujer es aquella mujer que no renuncia a tener su propia personalidad, que actúa según su iniciativa, que tiene una historia que contar- en resumen, una mujer que rechaza el papel sumiso" (Moi, 1999: 68-69). Coincide que ninguna de las mujeres que protagonizan las novelas de Assini ha ocupado un espacio notable en la historia, a pesar de su importancia, pero sí en la literatura un lugar donde han alimentado mitos y leyendas: Juana la loca, la condesa sangrienta, Semiramide la femme fatale, Juana de Arco, una mujer encerrada en un cuerpo de hombre, o Giulia y Girolama, dos frívolas asesinas. Figuras femeninas errantes, malditas, enajenadas y endemoniadas que Assini desnuda a través de la reescritura del pasado, rescatando su dignidad como mujeres y como extraordinarias que fueron. La escritora apuesta por volver a estas mujeres con el objetivo de "mostrar a la protagonista de manera distinta a otros historiadores" (Ciplijauskaité, 1988: 33).

Con ello, Assini presenta a mujeres históricas desde la perspectiva femenina, en la privacidad y cotidianeidad de sus vidas, y su trabajo consiste en cambiar "la escritura de la historia para insertar en ella preocupaciones más allegadas al mundo de la mujer; asuntos tales como la intimidad y las relaciones personales" (Juliá, 2006: 55). La novedad que introduce la escritora italiana en sus obras, muy dentro de la tradición de novela histórica femenina, es presentar a las mujeres y sus vivencias interiores, sus necesidades y la expresión de sus voluntades. Se puede decir, por lo tanto, que el punto de referencia de la historia es el sujeto -en este caso el sujeto femenino-, y gracias a ello el relato está dotado de cierta intimidad y profundidad psicológica, y trasladando a la mujer al eje principal de la acción.

\section{El caso de la reina Juana I}

Uno de los personajes más logrados de la obra de Adriana Assini es la protagonista de Le Rose di Cordova $a^{9}$ la Reina Juana I. La novela comienza cuando Juana era todavía una niña y se describe como una muchacha todavía en desarrollo, cuyas formas corporales femeninas eran aún incipientes por su temprana edad. La descripción de Juana irá cambiando a medida que los años pasan y el calvario que sufrió en vida le haga visible en ciertos rasgos físicos: "[Juana] conservaba igualmente el semblante de una adolescente ajada, con los ojos exageradamente grandes y oscuros en un rostro demasiado pálido y consumido" (Assini, 2011: 167). Juana, desde el inicio, se muestra como una mujer con una excelente instrucción, culta e inteligente y, a su vez, melancólica y reservada, pero no demente, como muchos historiadores han hecho creer. Su figura se puede decir que fue redescubierta en el siglo XIX gracias a las tesis de G.A. Bergenroth, Louis Prosper Gachard o Antonio Rodríguez Villa ${ }^{10}{ }_{L}$ entre otros. La relectura de los documentos oficiales dieron lugar a la reinterpretación de la historia

9 Le Rose di Cordova fue publicada en el 2007 por la editorial Scrittura \& Scritture y se tradujo al español en el 2011 gracias a la edición de Mercedes González de Sande.

10 Ciertos aspectos de las tesis de estos tres historiadores han sido desmontadas por otros años más tarde. Por ejemplo, Bergenroth, quien pasó varios años en el Archivo General de Simancas, retrató a la reina como "desleal o indiferente a la Iglesia Católica" (Aram, 2001: 13), convirtiendo su supuesta locura en un tema confesional. Louis Proper desmintió la tesis del alemán y señaló la reconciliación de la reina con dios al final de su vida. A pesar de las posibles conclusiones erróneas que pudieron extraer de sus investigaciones, sus tesis fueron de vital importancia por poner en duda, por primera vez, la locura de Juana. Todos ellos acusan a las condiciones de vida en las que Juana vivió como los motivos principales de una posible enfermedad. Ver: Bergenroth, G.A (ed), Letters, Despatches and State papers relating to the negotiations between England and Spain. Supplement to volumes and II, London, Longmans, 1868; Proper, L., "Jeanne la Folle et St. François de Borja" y "Les derniers moments de Jeanne la Folle", Bulletins de l'Académie Royale des Sciences, des Letters et des Beaux -Arts de Belgique, t. XXIX, Bruxelles, M.Hayez, 1870; Rodríguez Villa, A., La reina doña Juana la Loca. Estudio Histórico, Madrid, M.Murillo, 1892 
y, sobre todo, se avivó el debate acerca de su locura. La historia recoge la vida de una reina que, debido a una supuesta enajenación mental, fue incapaz de ejercer como monarca hasta tal punto de tener que ser encerrada en el castillo de Tordesillas, un cautiverio que durará casi medio siglo hasta su muerte en el año 1555. A pesar de la extendida noticia de su locura, paradójicamente, nunca se han encontrado documentos que confirmen su demencia o cualquier tipo de enfermedad mental que le incapacitara para reinar. Assini sigue estas pistas de la historia y decide reconstruir el personaje de Juana desde la cordura de la mujer. Así lo relata Nura, su compañera del alma, quien reconocerá sus extrañezas pero siempre negará su locura.

\section{Yo en aquella historia no había creído nunca, ni siquiera cuando quien la llamaba "loca" era su esposo. Al principionole daba importancia, pero enseguida comprendí que podía bastar un breve pero terrible adjetivo como aquél para marcar con fuego a quien se veía afectado por él. Y es que, mucho más allá del insulto, servía para ocultar las lagunas de algunos y los intereses de otros, la ignorancia de la ciencia y el mezquino interés de sus parientes (163)}

Voces como la de Pedro Mártir de Anglería o la propia Nura son testigos del origen de sus males que procedían, en parte, de su desafortunado matrimonio y de los juegos de poder de su padre: “Ella [...] asistía impotente a aquella farsa que veía alternarse continuamente la fortuna de los dos contendientes, un padre y un marido que no dudaban en sacrificarla en nombre de la avidez y del poder" (186).

A pesar de la influencia de su madre, la reina Isabel, Felipe dará un trato vejatorio a su hija algo contra lo que Juana luchará, olvidando el decoro y las buenas formas para tratar de hacerse valer y ser amada por el hombre con quien le obligaron casarse, rebelándose ante los caprichos del consorte, convirtiéndose así, en poco tiempo, un obstáculo para él. De hecho, hay quien interpreta la exteriorización del dolor como locura y otros, sin embargo, verán en ella los síntomas de la rebeldía. Encontramos a un personaje femenino que quiere rebelarse ante las convenciones de su tiempo, ante las injusticias que sufren las mujeres de su rango y, en definitiva, Juana es una mujer que sólo pide fidelidad y respeto. A lo largo de la novela vemos como ésta se impone ante su marido varias veces, exigiéndole disculpas, diciendo abiertamente los aspectos que detesta de su corte, sin importarle las apariencias o las consecuencias de un comportamiento subversivo. Esta firmeza se verá debilitada por el delicado escenario político del momento y las continuas ausencias de Felipe, que terminan por sumergir a Juana en una profunda soledad.

Como a un toro herido, le cayeron las babas por la boca, mientras se zarandeaba como los desgraciados afectados por la epilepsia [...] Después de gritos y alborotos, se replegó en sí misma como una flor cansada, prisionera de aquella sorda soledad que sólo el dolor puede soportar (138).
Pese a su convicción por tratar de cambiar el orden de las cosas, el dolor y el maltrato serán una constante en la vida de Juana. Ésta será encerrada en reiteradas ocasiones, tanto por su marido como por su padre, al considerarla una amenaza que podría poner en duda el poder de la familia. Cuando Juana hereda el trono, el primero en tratar de arrebatárselo será su marido:

[...] la astucia del yerno, que había hecho de su joven consorte una prisionera y la acosaba pidiéndole que renunciara al reino recién heredado [...] A causa de sus rebeliones, los rumores acerca de la locura de Juana aumentaban con desmesura, avalados también por el hecho de que, repentinamente, había dejado de lavarse y rechazaba obstinadamente alimentarse (184-185).

Juana no sólo trató de salvar su orgullo y la herencia que legítimamente su madre le había dejado sino que, además, luchó con los únicos medios que una mujer indefensa y subyugada puede utilizar: su cuerpo. Juana pasa así de salvarse del cautiverio al que le somete Felipe a volver a caer en otra prisión, esta vez de por vida: “Chantajeada y traicionada, esta vez, Juana bajó la cabeza y cedió la corona, lista para preparar su equipaje e instalarse en aquella fortaleza aislada [...] prometió solemnemente por su honor que de ahora en adelante obedecería ciegamente al soberano por su bien y el de España" (213).

Tordesillas no sólo le privará de la libertad sino que los golpes someterán a Juana físicamente, llegando a utilizar cuerdas contra ella, como si de un animal se tratase. La llegada de los comuneros ${ }^{11}$ empeoró todavía más su situación de aislamiento, trasladándola a una parte más recóndita y bajo la estricta supervisión del Marqués de Denia. El personaje de Juana demuestra en todo momento firmeza, no se tambalea ante la desgraciada vida que le espera. Continúa rebelándose, tomando una posición más distante hacia la religión y exigiendo algo que siempre consideró que merecía, un trato digno: "Juanita no dejaba de reivindicar, por escrito, su derecho a salir al patio o a comer carne en vez de sopa de col" (218). En el último año de su vida, se retrata a una Juana enferma, dolorida y postrada en una cama pero, aun así, utiliza la poca fuerza que tiene para gritar y exigir el respeto que merece una reina: “Repetía bien claro que ella era la reina de España y por eso exigía respeto, mientras quien tenía que protegerla no dudaba en hacerla callar a golpes de látigo, entre las carcajadas de los siervos" (228). Es por ello por lo que la castellana no logrará obtener respeto ni reconocimiento ni tan siquiera el día de su muerte, el momento en el que su voz se silenció al igual que se silenciaría su tormento en los libros de historia: “Me dije para mí misma que ni siquiera la muerte tenía intención de rendirle justicia a la soberana, negándole aquel pequeño tributo concedido incluso a sus caballerizos" (234).

11 En la novela se narra que el propio Padilla sometió a Juana a sangrías y exorcismos tras la renuncia de Juana al trono por considerar que estaba fuera de sí, confundida por los años de encierro. Es una muestra más de cómo Juana se convierte en un instrumento de poder para quienes la rodean. 
No hay duda de que la protagonista se presenta como una mujer rebelde, con una gran inteligencia y capaz de asumir los riesgos que conlleva el infligir las reglas. Assini retrata con gran pericia momentos de rebeldía y momentos de sufrimiento que llevarán a Juana a actuar de manera irracional, aunque justificada. La mayor parte de los momentos donde se puede ver a una Juana vencida y fuera de sí tienen que ver con el trato que recibe por parte de su marido o de su padre: “Después de gritos y alborotos, se replegó en sí misma como una flor cansada, prisionera de aquella sorda soledad que sólo el dolor puede soportar" (138); "Indiferente a los rangos, con escupitajos y patadas los ponía en la puerta, convirtiendo en un cordero incluso a hombres de la talla de Cisneros" (156). Escupe, insulta, propicia patadas y, en definitiva, se defiende y se rebela con su propio cuerpo y su voz. Sin embargo, mientras que muchos historiadores ${ }^{\frac{12}{2}}$ achacan este comportamiento rebelde a una locura posiblemente hereditaria, otros comenzaron a ver los orígenes de su desestabilización en la vida conyugal y en la rigidez de vida a la que Juana fue sometida desde muy pequeña en la corte de sus padres, "tra doveri e rigore, discorsi di morte ed echi di roghi" (Assini en González de Sande, 2009: 48)

Sin duda que el trato al que la sometió su esposo desde los primeros días de su matrimonio, y más que esto los celos fundadisimos que le dio con sus infidelidades y vida licenciosa, contribuyeron eficazmente a agravar la triste dolencia de Doña Juana, y, si se quiere, a producirla; por más de que imparcialmente haya que reconocer que causas análogas no producen de ordinario tales efectos, porque ¿cuántas mujeres, tratadas duramente por sus maridos infieles, conservan íntegro el uso de su razón? (Fabié, 1893: 103)

Tras una minuciosa investigación de las fuentes, Assini ve motivos más que suficientes para devolver a la reina la dignidad que la historia le arrebató, reviviendo su sufrimiento por un amor enfermizo y, a su vez, su entereza y rebeldía para enfrentarse a quienes la ultrajaron. Como la escritora afirma, "in realtà, la regina di Castiglia pagò lo scotto di una intelligenza superiore a quella dei suoi aguzzini, oltre al fatto di avere un carattere anticonformista e ribelle, caratteristiche imperdonabili nella Spagna arretrata e bigotta a cavallo tra XV e XVI secolo" (Assini en Cavallo, 2009: 24).

12 Ludwig Pfandl, Nicomedes Sanz y Ruiz de la Peña sostienen que Juana fue heredera de la posible esquizofrenia que sufría su abuela Isabel de Portugal o su madre la Reina Isabel de Castilla. No obstante, en la obra de Pfandl, la forma en la que el propio historiador trata a las mujeres deja en entredicho la veracidad de su tesis, pues la imagen que da de éstas es penosa. Por poner un ejemplo: "[...] las mujeres de la familia del marqués, además de enfadarse cuando Juana se obstinaba en sus cerrazones, también sentían placer en embarullarla aún más, sin compadecerse de ella, jMujeres, al fin y al cabo!" (1930: 98). Obviamente, Juana no sufrió vejaciones solo de mujeres, sino que más bien fueron los hombres quienes la maltrataron y confabularon contra ella. Además, relacionar a las mujeres con la crueldad de los hechos tratando de justificar éstos por medio de la naturaleza vil del sexo femenino, desde mi punto de vista, ofrece poco de objetivo, una muy pobre visión de la historia. De hecho, el título de la obra ya indica un cierto prejuicio contra Juana pues se llama, Juana la Loca madre del emperador Carlos V: su vida, su tiempo y su culpa. No sólo resalta el hecho de la locura sino que exalta antes su naturaleza de madre que de reina, dejando en segundo lugar la importancia que ésta tuvo para España y reduciendo su figura a locura y maternidad.
Una reina que ante todo fue mujer pero recibió el trato de un animal pues la trataron de someter con la violencia física y psicológica, siendo víctima de una manipulación debido a los intereses políticos de su familia para, más adelante, quedar enterrada en el olvido.

\section{ReFERENCIAS Bibliográficas}

Aram, B., La reina Juana: gobierno, piedad y dinastía, Madrid, Marcia Pons, 2001.

Assini A., Le rose di Cordova, Napoli, Scrittura \& Scritture, 2007.

-, "Tavolino riservato a Adriana Assini", I Caffe Culturali, 2008, Internet. 14-09-2010. http:// www.icaffeculturali.com/comunita/tavolino/AdrianaAssini\%20/Assini.htm

-, "Tavolino riservato a Adriana Assini", I Caffe Culturali, 2013, Internet. 16-2-2013. http:// www.icaffeculturali.com/comunita/tavolino/Assini\%20Adriana/Adriana\%20\%20Assini. htm

Aversa, Y., “Recensione: Adriana Assini, Un sorso d'arsenico”, Donne e conoscenza storica, 2009, Internet. 16-11-2011.

http://www.donneconoscenzastorica.it/decs15/index.php?option=com_content\&view=artic le\&id=199:libri-recensioni-adriana-assini-un-sorso-darsenico-scrittura-ascritture-napoli2009\&catid $=1$ :testi\&Itemid $=2$

Benfante, M., “L'ultimo dazio nella capitale del veleno”, La Repubblica, 02-04-2008.

Bonura, S., Le 101 donne più malvagie della storia, Roma, Newton, 2011.

Balza, I., "Identidades femeninas errantes: sobre hechiceras y monstruos", en Jaime de Pablos, E., (ed.), Identidades femeninas en un mundo plural, Sevilla, Arcibel, 2009.

Carù, P., “Uno sguardo acuto dalla storia: Anna Banti's Historical Writings”, en Marotti. M. O., Brooke, G., (ed.), Gendering Italian fiction: feminist revisions of Italian history, USA, Associated University Press, 1999.

Cavallo, C., Le Rose di Cordova di Adriana Assini. Traduzione di un romanzo tra storia e invenzione, Tesi di laurea Lingue Straniere per la Comunicazione Internazionale, Università di Bergamo, 2009

Ciplijauskaité, B., La novela femenina contemporánea (1970-1985). Hacia una tipología de la narración en primera persona, Barcelona, Anthropos, 1988

Fabié, A. M., “La reina Doña Juana la Loca, por D. Antonio Rodríguez Villa” Boletín de la Real Academia de la Historia, tomo 22, cuaderno I, 1983.

González de Sande, M.M., Las rosas de Córdoba, Traducción de la obra de Assini, A., Le rose di Cordova, Sevilla, Arcibel, 2011

Guarnieri, P., “Il mercante che diviene eroe", Leggere tutti, 59, 2011, pp. 64-65. 
Juliá, M., Las ruinas del pasado. Aproximaciones a la novela histórica postmoderna, Madrid, Ediciones de la Torre, 2006.

Matrone, P., "La dignità delle donne e le menzogne della storia nella scrittura colorata di Adriana Assini", Nuova Tribuna Letteraria, 109, 2013, pp.28-29.

Menton, S., La Nueva Novela Histórica de la América Latina, Méjico, Fondo de Cultura Económico, 1993.

Moi, T., Teoría literaria feminista, Barcelona, Cátedra, 1988.

Muñoz Páez, A., Historia del veneno: de la cicuta al polonio, Madrid, Debate, 2012.

Pandolfi, M., Itinerari delle emozioni: corpo e identità femminile ne Sannio campano, Milano, Franco Angeli, 1991.

Pfandl, L., Juana la Loca, madre del emperador Carlos V: su vida, su tiempo, su culpa, Madrid, Ediciones Palabras, 1930.

Repetto, G., "Il mercante di zucchero", Il paradiso degli Orchi. Rivista di letteratura contemporanea, 2011, Internet. 14-07-2012. http://www.paradisodegliorchi.com/Il-mercante-dizucchero26+M5449.aec.htlm

UAL., "Encuentros con Escritoras: Oriente y Occidente a través de la literatura femenina", Universidad de Almería, 2011, Internet. 15-6-2012.

http://cms.ual.es/UAL/universidad/organosgobierno/gabcomunicacion/noticias/15ABR2011_ ESCRITORAS2

Zambrano, M., “Eloisa o la existencia de la mujer", Anthropos, 2, 1987, pp. 79-86. 